Changes made to the teaching of linear algebra and calculus courses in the UK in response to the COVID-19 pandemic

M. Alarfaj ${ }^{a *}$, S. O’Hagan ${ }^{a}$ and C. J. Sangwin ${ }^{a}$

${ }^{a}$ School of Mathematics, University of Edinburgh, United Kingdom

*Saudi Electronic University, Saudi Arabia, m.alarfaj@seu.edu.sa

v2, 6 September 2021 


\title{
Changes made to the teaching of linear algebra and calculus courses in the UK in response to the COVID-19 pandemic
}

\begin{abstract}
In response to the COVID-19 pandemic, university mathematics departments in the UK adapted their teaching for 2020-21, with some courses being delivered digitally and others through a mixture of on-campus and digital delivery. A survey of linear algebra and calculus lecturers was carried out in the spring of 2021 to investigate what changes were made to courses, as well as lecturers' perceptions of institutional decision making and support. This survey found that a majority of the 41 participants were satisfied that the choice of delivery mode was correct, although views about the importance of offering on-campus classes were mixed. There was a significant increase in the use of video clips made by the lecturer, video-conferencing software, discussion forums, electronic submission of written work and on-screen marking tools. Most lecturers reported a reduction in the amount of time that students were expected to be taking part in live teaching activities and an increase in the amount of time they were expected to be working on asynchronous activities. While some were keen to return to their previous practice, others were enthusiastic about retaining features introduced in response to the COVID-19 pandemic.
\end{abstract}

Keywords: university mathematics teaching; COVID-19

\section{Introduction}

\subsection{Background}

The COVID-19 pandemic has forced university mathematics departments, and other educational institutions, to adapt at speed to new constraints on the way they teach. On 18 March 2020, the UK government, the Scottish government, the Welsh government and the Northern Ireland executive announced that schools would close to most pupils. Around the same time, university departments across the UK began to take unilateral action to pause or cancel on-campus classes (e.g. as announced by The University of Edinburgh School of Physics (2020)) and introduce emergency remote teaching. On 23 March 2020 governments across the UK announced emergency stay-at-home measures to slow the spread of COVID-19 that prevented on-campus teaching from taking place. Contingency measures were put in place by universities to complete the 2019-20 academic year.

In parallel, universities began to plan teaching activities for the 2020-21 academic year under the assumption that on-campus teaching would be difficult, limited or even impossible. Throughout the summer of 2020 discussions took place within university mathematics departments and across the academic community, facilitated by initiatives such as the newly-formed Teaching and Learning Mathematics Online (TALMO) conference, about how mathematics courses could be delivered digitally in 2020-21. This article aims to capture what actually happened in the delivery of university mathematics courses, specifically calculus and linear algebra courses, in 2020-21 and 
how any changes made might influence undergraduate mathematics teaching in the future.

\subsection{Theoretical framework}

To provide a theoretical framework for this investigation, we draw on the language of instrumental orchestration as discussed by Drijvers et al. (2010). An instrumental orchestration consists of three elements: a didactical configuration (the tools chosen by the teacher and how they are arranged), an exploitation mode (how the teacher intends for the arrangement of tools to be used) and a didactical performance (how the teacher and the students actually behave). As a community of mathematics educators, we have developed over many years a shared understanding of typical instrumental orchestrations used in undergraduate mathematics courses (see e.g. Artemeva \& Fox (2011) and Iannone and Simpson (2012)). This investigation attempts to understand the instrumental orchestrations used during 2020-21 and to determine whether any changes this year might lead to longer-term change in undergraduate mathematics teaching.

\subsection{Terminology}

Many new terms to describe teaching have entered the lexicon of mathematics educators over the past year or so. We define and use the following terms throughout this article to avoid ambiguity.

- On-campus teaching occurs with all participants in a university building; we use this term rather than face-to-face because digital teaching can also legitimately be described as face-to-face if cameras are used.

- Digital teaching uses platforms that can (at least in theory) be accessed no matter where the participants are physically located; we use this term rather than online to avoid confusion with entirely online courses or programmes.

- Live teaching is conducted in real-time, synchronously; asynchronous teaching is not live.

For example, students reading a textbook in their own time is asynchronous, students interacting on a forum is asynchronous and digital, students working through a problem sheet in a classroom setting may be live and on-campus, and a lecture may be live and digital or live and on campus.

\subsection{Research questions}

To address the aim of recording changes to teaching practices in early university mathematics courses, and how those changes might influence undergraduate mathematics teaching in the future, we focus on five specific research questions.

(RQ1) What modes of delivery were used in 2020-21 for undergraduate mathematics teaching in the UK and did lecturers feel these were appropriate? 
(RQ2) Did those lecturing undergraduate mathematics courses in the UK feel that their institutions were prepared for digital delivery in 2020-21?

(RQ3) How did the teaching tools used change as a result of the COVID-19 pandemic?

(RQ4) How did expectations made of students change as a result of the COVID-19 pandemic?

(RQ5) Do lecturers intend to keep any changes to teaching made as a result of the COVID-19 pandemic in the longer term?

These research questions attempt to help understanding of instrumental orchestrations to use the language of Drijvers et al. (2010) - used by mathematics lecturers in 2020-21 and how these have changed as a result of the COVID-19 pandemic. RQ1-RQ3 aim to understand didactical configurations used; RQ4 is an attempt to understand exploitation modes and didactic performances. RQ5 is intended to capture lecturers' overall attitudes to changing instrumental orchestrations in the teaching of university mathematics.

\section{Method}

\subsection{Design of and administration of survey}

A simple survey was designed with a mixture of open-response, multiple-choice and Likert scale questions. Participation was sought only from those teaching a first course in calculus or linear algebra. Calculus and linear algebra are the only two subjects named explicitly as being common to mathematics degrees in the QAA's Subject Benchmark Statement for Mathematics, Statistics and Operational Research (2019), and so every mathematics undergraduate student should study these subjects. Focussing on these courses means that responses to the survey are more directly comparable than if participants had been teaching a broader range of subjects. However it is acknowledged that this restriction does skew the results to courses which typically have larger classes and are taught in the earlier years of undergraduate study.

The survey was administered electronically using JISC Online Surveys and responses were invited using the authors' professional networks, the Heads of Departments of Mathematics (HoDoMs) mailing list and a call in an email announcement by Teaching and Learning Mathematics Online (TALMO).

The study was conducted according to the University of Edinburgh ethics procedures. The survey questions and the anonymised data, along with notes made during analysis and code used for analysis, are available at https://osf.io/6pujb.

\subsection{Analysis of responses}

In Question 7 of the survey, lecturers were asked to indicate from a list of digital tools which they had used before the COVID-19 pandemic and which they had used in the 2020-21 academic year. To determine which tools had seen significant change in their use, the data for each tool were subjected to the mid- $p$ version of the McNemar test. This particular version of the McNemar test was chosen over the more common asymptotic McNemar test, following Fagerland et al. (2013), due to the modest sample 
size. To correct for the fact that multiple hypotheses were being tested simultaneously, and so rare occurrences were more likely to be observed in the results (the so-called multiple testing problem), the Holm-Bonferroni method (Holm, 1979) was used to identify those tools with evidence of a significant change at the 5\% level. The HolmBonferroni method was preferred to the more conservative Bonferroni correction (where an adjusted $\alpha=0.05 / 15 \approx 0.003$ would have been used for each hypothesis test) to reduce the risk of not detecting a significant change. However, the figures in Table 2 (see page 12) show that using the standard Bonferroni correction would have resulted in the same conclusion; that is, the same tools were identified as having seen a significant change in their use.

In Question 9, participants were invited to describe any other tools that had been used in 2020-21 and to specify whether these tools had been used before the COVID-19 pandemic. On inspection of the responses to Question 9, some of the tools fell into the categories listed in Question 7. In each of these cases, the responses given in Question 7 were checked for consistency with those given in Question 9; in one case, a response to Question 7 was modified accordingly. Notes were kept in the spreadsheet of survey results.

The open-response questions $(5 \mathrm{~b}, 8,9,11,12$ and 14-18) were analysed to identify common themes. Initially responses were coded according to the themes that they contained by one of the authors. All three authors then met together, looked through the themes and coding, and any disagreements were discussed and resolved by consensus.

\section{Results}

In total, 44 participants completed the survey between 22 March and 2 June 2021. Question 2 was used to screen out participants who had not taught either a first course in linear algebra or a first course in calculus in 2020-21. Four participants chose the option "Other" in response to this question; of these, two had taught second year courses and the third was ambiguous about the year of the course; these three responses were excluded from the analysis. The fourth participant who chose "Other" described their course as "The 2nd of two first year courses, mostly calculus with some vectors/geometry" and so this response was not excluded from the analysis.

The sample consists of 41 lecturers; 20 had been responsible for delivering a first course in linear algebra, 20 a first course in calculus, and one as described in the previous paragraph. Of these, 34 chose to identify their institution. There were participants from at least 21 distinct UK institutions; 20 in England and one in Scotland. At least six of the institutions are members of the Russell Group. There were seven participants in the sample who chose not to identify themselves or their institution. To put these numbers in context, the Complete University Guide lists 72 departments in its UK Mathematics Subject League Table 2022, suggesting that the survey had a reasonably high response rate. 


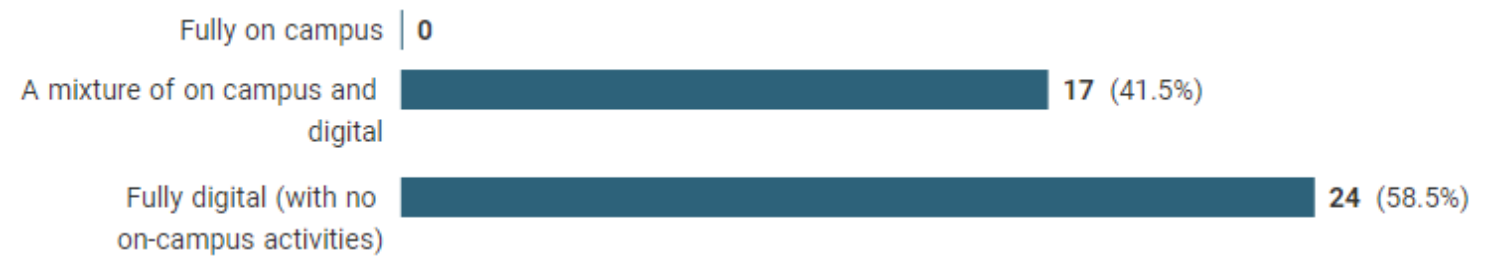

Figure 1. Summary of responses to Question 4: In 2020-21, what was the mode of delivery of your course?

Table 1: The number of courses delivered through on-campus and digital activities in different terms.

\begin{tabular}{|r|r|r|r|} 
& \multicolumn{1}{c}{$\begin{array}{l}\text { A mixture of on } \\
\text { campus and digital }\end{array}$} & $\begin{array}{l}\text { Fully digital (with no } \\
\text { on-campus activities) }\end{array}$ & \multicolumn{1}{c|}{ Total } \\
\cline { 2 - 5 } Before Christmas 2020 & 10 & 11 & $\mathbf{2 1}$ \\
\cline { 2 - 5 } After New Year 2021 & 1 & 9 & $\mathbf{1 0}$ \\
\cline { 2 - 5 } Whole academic year 2020-21 & 6 & 4 & $\mathbf{1 0}$ \\
\cline { 2 - 5 } Total & $\mathbf{1 7}$ & $\mathbf{2 4}$ & $\mathbf{4 1}$ \\
\cline { 2 - 6 } & & &
\end{tabular}

A small majority of lecturers $(24$ of $41 ; 58.5 \%)$ reported that their course had been delivered digitally with no on-campus activities in 2020-21. The remainder were delivered through a mixture of digital and on-campus activities. There were no courses delivered fully on campus in 2020-21. There was a marked shift in the mode of delivery after New Year 2021 with 9 of the 10 courses delivered in this period being fully digital. Note that during October and November 2020, tiered systems designed to control the spread of COVID-19 were introduced by governments across the UK. On 19 December 2020, in response to rising cases of the Alpha (Kent) variant of COVID-19, more restrictive measures were introduced in parts of England, in Scotland and in Wales. These measures constrained on-campus teaching activities, and likely explain the shift towards digital delivery after New Year 2021.

The responses to the question "Who made the decision about the mode of delivery?" are summarised in Figure 2. 


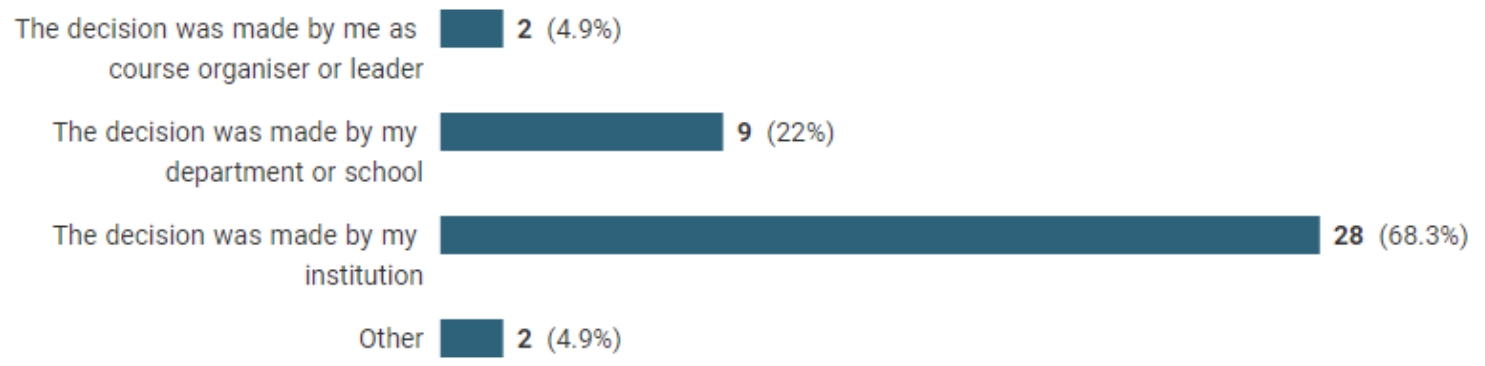

Figure 2. Responses to Question 5: Who made the decision about the mode of delivery?

The two lecturers who responded "Other" both suggested there was no decision to be made since government restrictions had forced them into digital delivery, and indeed these courses were both delivered after New Year 2021.

"We would have had some on campus sessions but the national lockdown prevented them from happening."

"Decision made by UK government. Have put mixture, but so far all online. Hope/expect to be in person for 4 weeks after Easter break"

Of those who expressed an opinion, there was near unanimity that the mode of delivery used had been the correct one given the circumstances. Some lecturers who had offered on-campus classes felt that these had been worthwhile even when delivered under restrictions.

"I think it was correct, fully online would be worse, even the chance of having some in-situ examples classes were useful."

"Yes - it would not have been possible to have all events on campus but those students who were able to attend in-person events benefited from them."

Several lecturers were concerned that students had lacked the opportunity for social interaction and that more on-campus teaching activities would have been beneficial for this purpose.

"The first year students would have benefitted more from more on-campus activity. The social cohesion of the students hasn't been great."

Others who had offered on-campus classes commented that these were poorly attended by students.

"To some extent. Some element of in-person teaching was allowed, and reasonable to provide; however, it was hard to do, and attendance was very poor."

"We offered both: On-campus and online tutorials. There were handful of students attending on campus, towards the end of Semester 1 we had to cancel some on- 
campus classes due to no attendance. Probably we could have organised all classes online with much less admin workload for the module organiser to organize and run both options."

One lecturer commented that, in their experience, while some teachers preferred to give on-campus sessions, the physical-distancing restrictions impinged so much on the operation of the class that offering fully digital classes was preferable for learning. However, they did concede that students may have missed out on the social aspect of on-campus teaching.

"Some of the problem class leaders preferred the on campus versions, but the group work we usually do in those sessions made the safety very difficult. And on campus sessions were cut much shorter due to cleaning time. So educationally and from a health perspective, (though perhaps not socially), I think it was better online."

Only two lecturers said explicitly that they felt the choice to have on-campus classes had been wrong. One cited the increased workload involved in delivering physicallydistanced classes as the reason against offering on-campus activities.

"No. I had to repeat the same material 4 times for different groups of students. That is not reasonable."

The other felt that having on-campus classes during a pandemic had put staff at risk.

"No. The students should never have been in the classroom at all, and the school put the life of the TA at risk by doing so."

Almost all lecturers who had delivered courses digitally with no on-campus activities felt had been the correct decision. The most common reason given for fully digital delivery was having no other option given the pandemic ( 29 of 38; 47.4\%). Concerns around providing an equitable experience to overseas students or those otherwise unable to attend on-campus activities were also mentioned by some ( 3 of $38 ; 7.9 \%$ ). One expressed regret that there had not been on-campus activities as they felt students would have benefitted from these.

"Yes for lectures, no for tutorials. However, I am fully appreciative of the COVID situation and was more than happy to deliver entirely online. But students have suffered with no face to face contact."

Another gave the saving of increased workload as a reason in favour of digital delivery.

"The class really was too large to have socially distant in-person lectures (without having to at least triple teach). However students engaged reasonably well with the online material offered." 


\subsection{Perceptions of institutional preparedness for digital delivery (RQ2; survey Q6)}

A summary of the responses to Question 6 are shown in Figure 3.

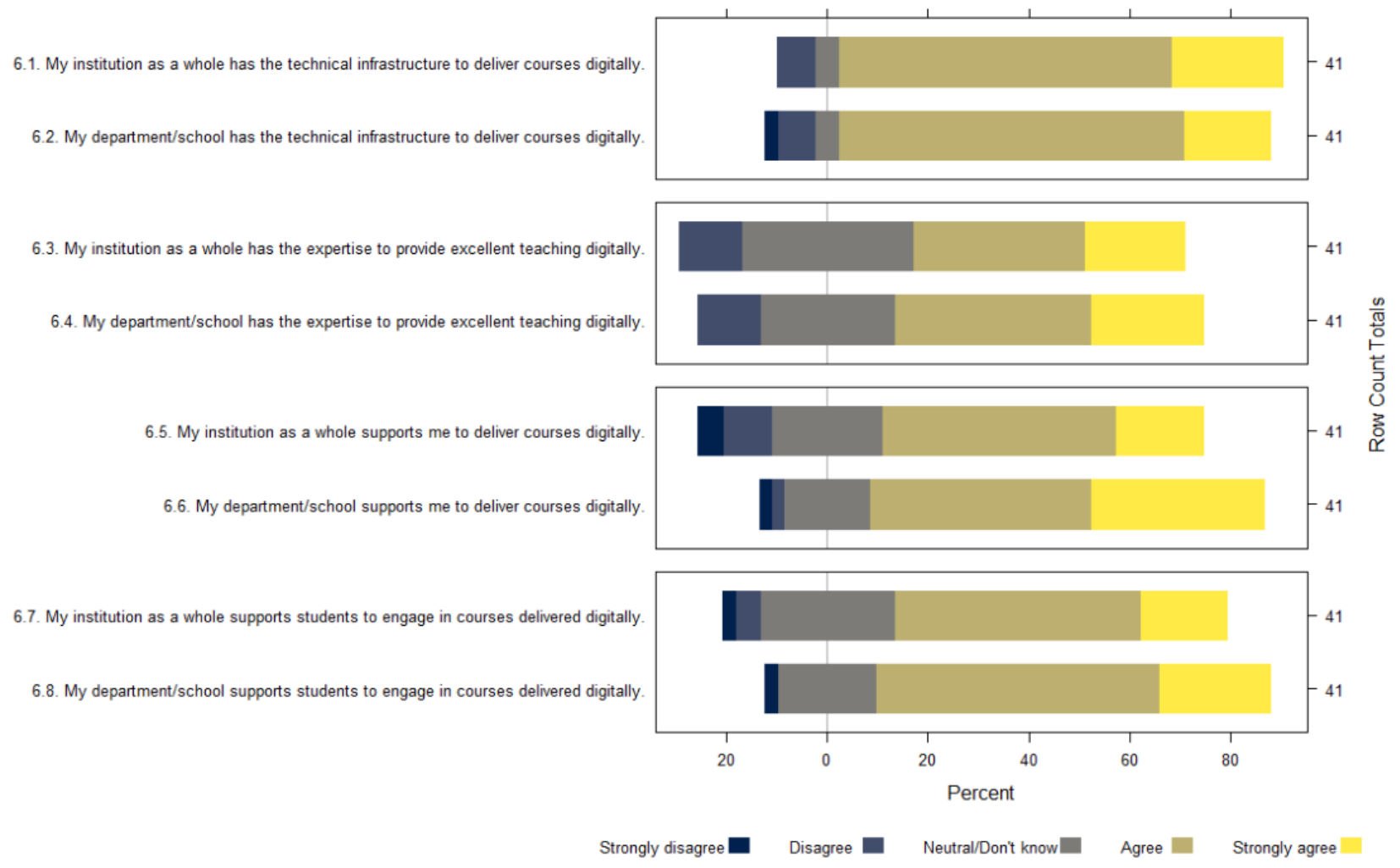

Figure 3. Summary of responses to Question 6: For each of the following statements, please choose the option which most closely aligns with your view.

The vast majority ( 36 of $41 ; 87.8 \%$ ) of participants agreed ( 27 of $41 ; 65.9 \%$ ) or strongly agreed $(9$ of $41 ; 22.0 \%)$ with the statement "My institution as a whole has the technical infrastructure to deliver courses digitally", with only three participants disagreeing; two did not know or were neutral. Confidence in technical infrastructure at a departmental level was similarly high; again, the vast majority ( 35 of $41 ; 85.4 \%$ ) agreed ( 28 of 41 ; $68.2 \%)$ or strongly agreed $(7$ of $41 ; 17.1 \%)$ that "My department/school has the technical infrastructure to deliver courses digitally".

However, there was less confidence that institutions and departments have the expertise to provide excellent teaching digitally. The majority of those who expressed a view felt that their institution as a whole had the expertise to deliver excellent teaching digitally. But the most common response to this question was "Neutral/Don't know" (14 of $41 ; 34.1 \%$ ). More participants ( 25 of $41 ; 61.0 \%$ ) agreed ( 16 of $41 ; 39.0 \%$ ) or strongly agreed $(9$ of $41 ; 22.0 \%)$ that their department had this expertise, but still a substantial number said they were neutral or did not know (11 of $41 ; 26.8 \%$ ). Of those who agreed that their department had the technical infrastructure to deliver courses digitally, three lecturers $(7.3 \%)$ also disagreed that their department had the expertise to provide excellent teaching digitally. A further seven (17.1\%) said they were neutral or did not 
know if their department had that expertise. There are many possible reasons for these results: it may be that a shared sense of what constitutes excellence in digital teaching had not developed in UK mathematics departments or that communication within some departments during the pandemic had been difficult.

When it comes to feeling supported to deliver courses digitally, the vast majority of participants (32 of $41 ; 78.0 \%$ ) agreed (18 of $41 ; 43.9 \%$ ) or strongly agreed (14 of 41 ; $34.1 \%$ ) with the statement "My department/school supports me to deliver courses digitally"; seven did not know or were neutral and two disagreed (1 of $41 ; 2.4 \%)$ or strongly disagreed ( 1 of $41 ; 2.4 \%$ ). Inspection of Figure 3 suggests that participants felt more supported by their departments than by their institutions as a whole; this is perhaps unsurprising as it seems natural that lecturers would be more likely to interact with and seek support from colleagues within their own department rather than central university services. Another possible explanation is that centralised support provided by universities may not have addressed the specific needs of mathematics lecturers, such as how to share writing containing mathematical notation.

Participants had more confidence that students were supported by their department, rather than their institution as a whole, although most respondents agreed or strongly agreed that they felt students had been supported to engage with digital activities.

\subsection{Tools used in teaching (RQ3; survey Q7, Q8, Q9)}

Responses to Question 7 of the survey are summarised in the alluvial plots in Figure 4 (page 11). Each of these plots shows the proportion of participants using a given tool before COVID-19 and during 2020-21, and indicates those whose use changed in the interim. Take, for example, the plot labelled "7.1 Virtual learning environments (VLEs)". This shows that 34 participants indicated they had used a VLE before COVID19 , and the remaining seven responded that they had not. Two of those who had used a VLE before COVID-19 had not done so in 2020-21 and three who had not used a VLE before COVID-19 started to do so in 2020-21; the shaded areas between the two bars in the plot illustrate these changes. In 2020-21, 35 participants used a VLE and six did not. The results of the statistical analysis described in Section 2.2 are shown in Table 2 (page 12).

Six tools saw a significant increase in their use. These were: (i) video clips made by the lecturer, (ii) video-conferencing software, (iii) business communication platforms, (iv) discussion forums, (v) electronic submission of written work (human marked) and (vi) on-screen marking tools. None of these results are surprising given the shift towards greater digital delivery, but these results do provide a record of changes that have occurred within this sample of mathematics departments across the UK. 


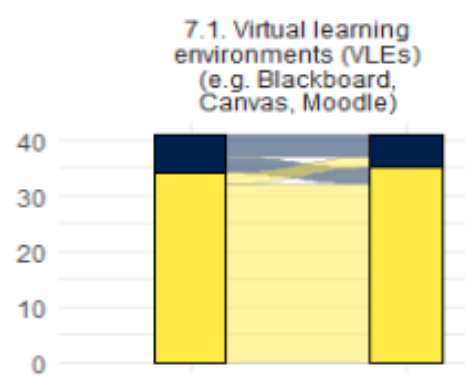

7.4. Digital textbook as primary resource

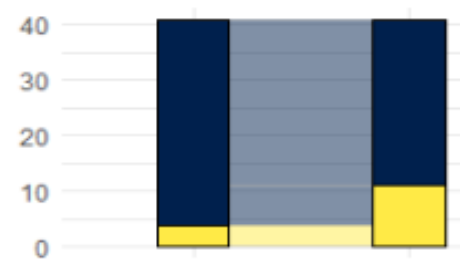

7.7. Audience response systems (e.g. Top Hat, Zoom polls, Kahoot!)

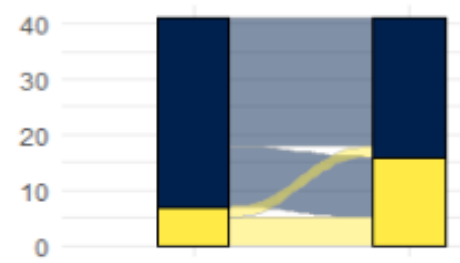

0

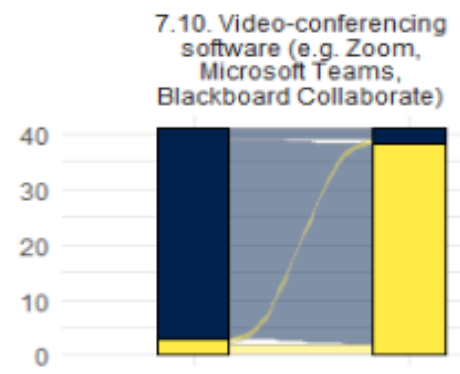

7.13. Electronic submission of written work (human marked)

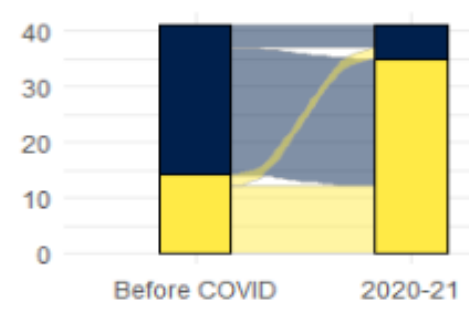
7.2. Typed course notes
(e.g. in PDF format or on the web)

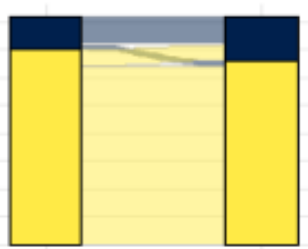

7.5. Video clips made by you

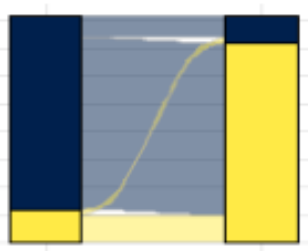

7.8. Discussion forums

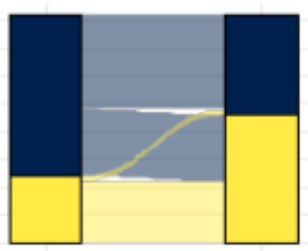

7.11. Business communication platforms (e.g. Slack, Microsoft Teams, Mattermost)

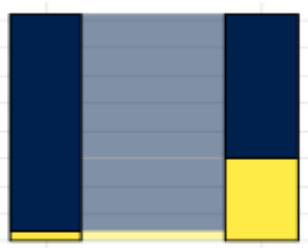

7.14. On-screen marking tools (e.g. Turnitin. Gradescope)

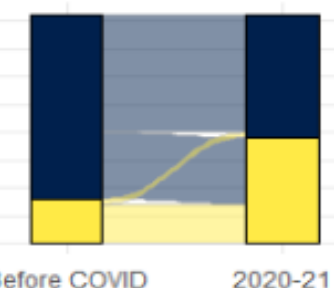

7.3. Physical textbook as primary resource + digital subscription

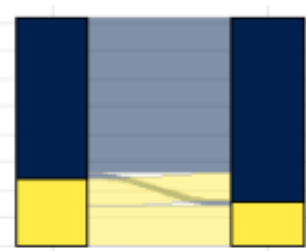

7.6. Video clips made by someone else

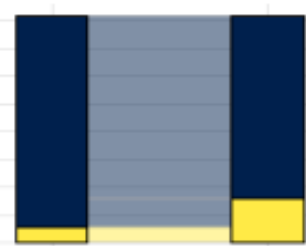

7.9. Social media (e.g. Facebook)

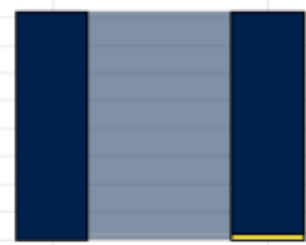

7.12. Online assessment platforms (e.g. STACK, Numbas)

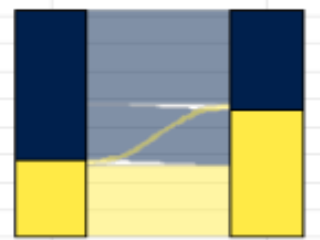

7.15. Specialist software for mathematics (e.g. GeoGebra, Desmos)

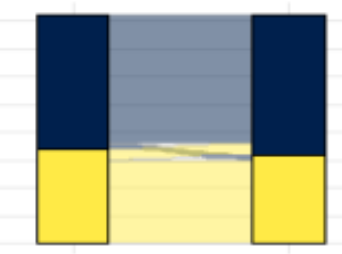

Before COVID

2020-21

Figure 4. Summary of responses to Question 7: Thinking about how you would have delivered (or did deliver) the same course before the COVID pandemic, which digital tools would you have used (or did you use)? And which of these tools have you used to deliver the course in 2020-21? 
Seven of the tools were used by more than half of respondents in their teaching in 2020-21: (i) virtual learning environments (VLEs), (ii) typed course notes, (iii) discussion forums*, (iv) video clips made by the lecturer*, (v) video conferencing software*, (vi) online assessment platforms, and (vii) electronic submission of work (human marked)*. Taken together, these appear to make up a common toolkit used to teach mathematics digitally. The four tools marked * also saw their use increase significantly from pre-COVID times, according to the analysis above, suggesting that there has been a major change in the tools used to teach first-year undergraduate mathematics in response to the COVID-19 pandemic.

Table 2: Results of the statistical analysis of responses to Question 7. Six tools saw a significant change in use in 2020-21 as compared to before the COVID-19 pandemic.

\begin{tabular}{|c|c|c|c|c|c|}
\hline Tool & Unadjusted $p$ & Rank & Adjusted $p$ & Adjusted $\alpha$ & Significance \\
\hline Video clips made by you & 0.0000 & 1 & 0.000 & 0.003 & sig \\
\hline $\begin{array}{l}\text { Video-conferencing software } \\
\text { (e.g. Zoom, MS Teams, BB Collaborate) }\end{array}$ & 0.0000 & 2 & 0.000 & 0.004 & sig \\
\hline $\begin{array}{l}\text { Electronic submission of written work } \\
\text { (human marked) }\end{array}$ & 0.0000 & 3 & 0.000 & 0.004 & $\operatorname{sig}$ \\
\hline $\begin{array}{l}\text { Business communication platforms } \\
\text { (e.g. Slack, Microsoft Teams, Mattermost) }\end{array}$ & 0.0001 & 4 & 0.001 & 0.004 & sig \\
\hline Discussion forums & 0.0018 & 5 & 0.020 & 0.005 & sig \\
\hline $\begin{array}{l}\text { On-screen marking tools } \\
\text { (e.g. Turnitin, Gradescope) }\end{array}$ & 0.0018 & 6 & 0.018 & 0.005 & sig \\
\hline $\begin{array}{l}\text { Online assessment platforms } \\
\text { (e.g. STACK, Numbas) }\end{array}$ & 0.0063 & 7 & 0.057 & 0.006 & non-sig \\
\hline Digital textbook as primary resource & 0.0078 & 8 & 0.062 & 0.006 & non-sig \\
\hline $\begin{array}{l}\text { Audience response systems } \\
\text { (e.g. Top Hat, Zoom polls, Kahoot!) }\end{array}$ & 0.0129 & 9 & 0.090 & 0.007 & non-sig \\
\hline Video clips made by someone else & 0.0312 & 10 & 0.187 & 0.008 & non-sig \\
\hline $\begin{array}{l}\text { Physical textbook as primary resource + } \\
\text { digital subscription }\end{array}$ & 0.1250 & 11 & 0.625 & 0.010 & non-sig \\
\hline $\begin{array}{l}\text { Typed course notes } \\
\text { (e.g. in PDF format or on the web) }\end{array}$ & 0.3750 & 12 & 1.500 & 0.013 & non-sig \\
\hline Social media (e.g. Facebook) & 0.5000 & 13 & 1.500 & 0.017 & non-sig \\
\hline $\begin{array}{l}\text { Specialist software for mathematics } \\
\text { (e.g. GeoGebra, Desmos) }\end{array}$ & 0.6250 & 14 & 1.500 & 0.025 & non-sig \\
\hline $\begin{array}{l}\text { Virtual learning environments (VLEs) } \\
\text { (e.g. Blackboard, Canvas, Moodle) }\end{array}$ & 0.6875 & 15 & 1.500 & 0.050 & non-sig \\
\hline
\end{tabular}

In Question 8 participants were invited to describe any other tools that they used before the COVID-19 pandemic but that they did not use in 2020-21. There were responses from 20 of the 41 participants. All respondents described tools or activities that would have been used in traditional on-campus mathematics classrooms such as "Live in person lectures!", "Chalk, markers and boards", "A proper blackboard" and "Physical whiteboard and marker pens. Overhead projector.".

Digital tools such as visualisers and projectors, also associated with on-campus delivery, were mentioned by five (25\%) respondents. Some participants mentioned tools 
such as tablets that, although used for on-campus teaching, might prove useful in the future for capturing hand-written notes made during class. One participant mentioned that they had handed out printed notes in the past but did not do so in 2020-21.

In Question 9 participants were asked to describe any other tools that they had used in 2020-21 and whether they had used them before the COVID-19 pandemic. There were two tools in the responses that were mentioned by more than one participant, namely: (i) writing tablets, mentioned by five participants; and (ii) online collaborative whiteboards (those named were Miro and OneNote), mentioned by two participants.

\subsection{Expectations made of students (RQ4; survey Q10, Q11, Q12, Q13, Q14)}

In Question 10 of the survey, participants were asked how much time students had been expected to participate in live teaching activities during 2020-21 compared with before the COVID-19 pandemic. In Question 11, they were asked to explain why this was the case. Responses to Question 10 are summarised in Figure 5. A large majority of respondents ( 30 of $41 ; 73.2 \%$ ) said that students had been expected to spend less time taking part in live activities than in previous years; only four $(9.8 \%)$ said students were expected to spend more time, and seven just the same as before $(17.1 \%)$.

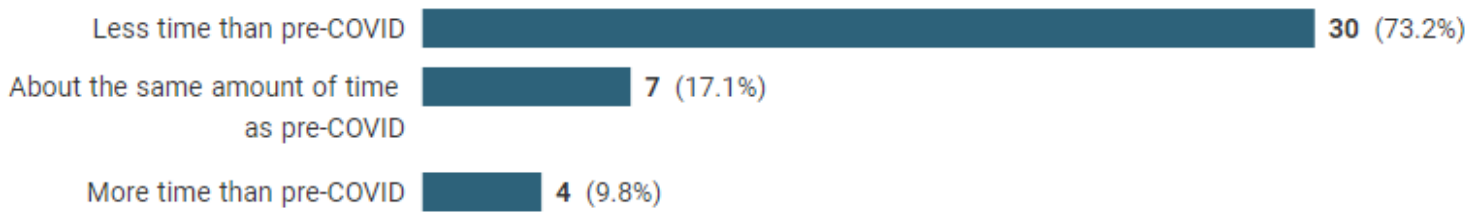

Figure 5. Responses to Question 10: In a typical week of your course in 2020-21, how much time did you intend for students to spend taking part in live activities compared with what you would have intended pre-COVID?

Continuity with previous years was mentioned by all five of those who gave reasons for expecting the same amount of time on live activities as before the pandemic. One participant suggested two arguments in favour of running sessions live, even if done digitally: to cater for student preference and to avoid the workload associated with preparing video clips.

"[The amount of time is the same] Because I've continued to do essentially everything live. The students seem to prefer it like this, and saves me time as I don't need to spend lots of time preparing recordings."

Of those who said that expected time participating in live sessions had increased, a common reason was the introduction of additional support sessions for students.

Among those who expected less live participation from students, the vast majority $(27$ of $29 ; 93.1 \%$ ) referred to a reduction in the use of live lectures. Most (22 of 29; $75.8 \%$ ) said that these had been replaced by pre-recorded video clips. The Teaching and 
Learning Mathematics Online (TALMO) meetings were mentioned by one participant as having influenced choices about how to run courses.

"We decided, given lots of advice (including TALMO), that a mix of live lectures and some pre-recorded videos would work best."

Some of the participants ( 4 of $29 ; 13.8 \%$ ) had concerns about the access to and the reliability of digital technology for giving live digital classes. There were concerns about students not having adequate software, hardware, a suitable working environment, or internet connection to participate fully in live digital classes and also about reliability of software at the lecturer's end.

When asked, in Question 12, if the nature of live activities had changed compared to before the COVID-19 pandemic, all respondents suggested that changes had occurred. A sizeable number of participants suggested they had reduced the use of traditional lectures in place of other activities. Most common was replacing lectures with video clips and introducing office hours, in-class polling for more interactive sessions, Q\&A sessions or review lectures.

"No live lectures were given. Instead live sessions were combined review/discussion of extra examples. These were much more interactive than traditional lectures."

Just under one third of respondents (13 of 41; 31.7\%) said they felt they had less interaction with students during live classes. Reasons given included the apparent reluctance of students to appear on camera and speak out in digital classes, as well as difficulties seeing the reactions of the audience.

"Yes. It was difficult to gauge engagement when practically all students did not have cameras nor microphones on during any teaching sessions. Usually it is easy to tell if students are engaged when it is face to face, but not online."

"Online stopped my giving examples to answer audience questions. Harder to gauge audience reactions - could not see faces with expressions of understanding."

More than a third of respondents $(15$ of $41 ; 36.6 \%)$ reported an increase in interaction of some kind with students during live activities, though sometimes through nontraditional means. Those who had designed live classes to encourage participation from students (for example through the use of a flipped classroom, in-class polling or Q\&A sessions) seemed to report success.

"I did flipped classroom for the first time, encouraged by the Covid online situation. So the live sessions were entirely different to what I used to do before. Much much more interactive, with the lecturing of new material done in prerecorded videos instead."

Several participants $(5$ of $41 ; 12.2 \%$ ) mentioned that students seemed to prefer to make contributions using the text chat instead of speaking out during live classes. A few felt that this was a disadvantage. 
"live seminars were less interactive due to students not switching on cameras and using time-consuming chat instead of speaking up"

Others saw the increased students participation as an advantage.

"A bit more interactive now they are on MS Teams - students seem more happy to type questions or point out my mistakes via the 'chat' compared to speaking out in a lecture theatre. Students also don't wait for me to give them time to ask questions (even though I do), they just ask things at any time (in the 'chat') - which is nice."

In Question 13 of the survey, participants were asked how much time students had been expected to participate in asynchronous activities during 2020-21 compared with before the COVID-19 pandemic. The responses to this question are summarised in Figure 6. A large majority of respondents $(28$ of $41 ; 68.3 \%$ ) said that students had been expected to spend more time taking part in asynchronous activities than in previous years; only four $(2.4 \%)$ said students were expected to spend less time, and $(29.3 \%)$ just the same as before. As expected, these results broadly mirror the changes in expectations of student participation in live activities discussed above.

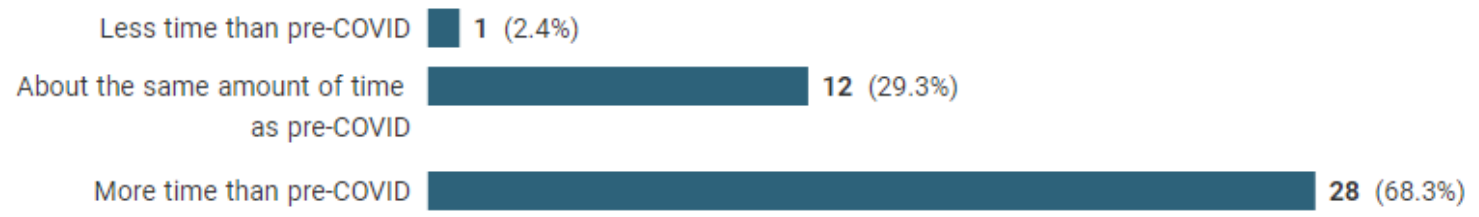

Figure 6. Responses to Question 13: In a typical week of your course in 2020-21, how much time did you intend for students to spend working on asynchronous activities compared with what you would have intended pre-COVID?

In Question 14, participants were asked if students had acted as the lecturer had intended when designing the course, and on what evidence this judgement was based. More than a third (13 of $37 ; 35.1 \%$ ) of the respondents said they thought students had broadly acted as intended, around a tenth (4 of 37; 10.8\%) suggested students had not acted as intended, around one fifth ( 8 of $39 ; 21.6 \%)$ said there had been a mixed response, and the same number ( 8 of $39 ; 21.6 \%$ ) indicated that they did not know how students had behaved.

Among the respondents who described how they had gauged student activity, most common was the use of some form of online activity tracking (14 of 37; 37.8\%), for example the number of times a video clip had been viewed or reports from virtual learning environments.

"Surprisingly, they did reasonably well. The lectures had stats for how much they were used, and for most of them the students were engaging at reasonable levels."

The next most common measure of how students had behaved was their engagement in 
live classes, which may have been digital or on-campus ( 7 of $37 ; 18.9 \%$ ). These respondents largely described a mixture of behaviour.

"I think the engaged students did work well and interacted with the material as intended. But there was a huge drop-off of engagement in the second semester (throughout the whole uni, as far as I've heard). Judging from lecture attendance and polls at the start of nearly every lecture on whether they had watched the prerecorded videos and done the questions, there was reasonable engagement in the first semester (higher lecture attendance than in previous year for longer), but much lower in the second semester (much less than in previous years)."

"There are some trends to show deeper engagement, based on questions asked during live sessions and office hours."

A couple of respondents reported that students had not been keen to speak out in live digital classes.

"In tutorial classes students were to work on preset problems (formative type assessment) but none of them actually engaged. That goes for all years. Actually, first years a lot more engaged than others, but engagement was still extremely low."

Several responses ( 5 of $37 ; 13.5 \%$ ) mentioned that student attainment in coursework had been in line with expectations.

"The performance in assessments so far seem as good as in previous years, but we need to wait and see how the final exam goes. If it goes just as well as previous years, this will be evidence that students have engaged."

Three of the responses $(8.1 \%)$ suggested that lecturers felt some students had struggled with motivation and keeping pace with the course, as well as missing out on social interaction.

"Insofar as I can judge there has been a bifurcation, with around half the students fully engaging as intended, but another half struggling to maintain work levels without the discipline of physical attendance and interaction with coursemates."

"I think that many students did not watch the lecture recordings in full, but it is also true that many students chose not to attend the 'normal' pre-Covid lectures. I think that the overall situation (lockdowns, not being able to create new friends and work in groups) was more harmful to the student education than the move to remote teaching."

\subsection{Looking to the future (RQ5; Q15, Q16, Q17, Q18)}

In Question 15 of the survey, participants were asked to think about the digital tools they had used in their course delivery in 2020-21, and whether they intended to keep 
any changes to teaching made as a result of the COVID-19 pandemic.

A tenth of respondents ( 4 of 40) suggested that they would like to return to the tools used before the COVID-19 pandemic. The rest expressed an intention to retain at least some of the changes that they had made for 2020-21. The most common feature that lecturers would like to keep in the longer term was video clips (17 of 40;42.5\%). Five of these suggested they felt recorded lectures would be helpful resources for students.

"I may use the recorded video lectures as additional revision materials in the future. Students always appreciate having more help with their revision."

"It would be better to teach in-person lectures and problem classes, but the recorded material from this past year would be a helpful resource."

One suggested keeping the video recordings to help cater for students with varying prior attainment.

"Use of video material. There are parts of the course where students have varied background. Students who haven't seen the material at A-level can access the material at their own pace."

Of those who responded, 14 (35\%) suggested that they would like to keep online assessment platforms. The reasons given included allowing students more practice with immediate feedback and preventing cheating on tests through question randomisation.

"I am planning to continue using STACK tests, since they worked very well, and are good both as a form of formative assessment and for providing immediate feedback. Finally, they make copying work from other students nearly impossible (although other forms of cheating may still be taking place)."

Nine lecturers (22.5\%) said they would consider some form of flipped classroom, continue to use in-class polling or expressed a desire to have live sessions be more interactive than traditional lectures.

"I would keep the record lecture components and use future real-time teaching activities in more imaginative ways."

"I think polling is good because it gives the shy students the opportunity to still engage anonymously."

There was intention from four lecturers $(10 \%)$ to keep at least one of discussion forums, business communication platforms and electronic submission of coursework.

In Question 16 participants were asked to think about the mix of live and asynchronous activities they had used in their course delivery in 2020-21, and whether they would consider using a different mix of activities than they would have traditionally once the COVID-19 pandemic is over. Half of the respondents (18 of 36) answered suggesting that they would like to go back to delivering courses largely as 
they had done before the pandemic, but with some indicating that they would like to retain video clips for use as an additional resource.

"I felt that live teaching is always better than asynchronous."

"I prefer to go back to the balance of classes that we had before the pandemic. Many students benefit from the face to face interaction. But I would like to make the recordings of lectures available for students that can't attend or need to watch twice."

Most of the remaining respondents (11 of $36 ; 30.6 \%$ ) said that they would consider running their courses with a different mix of live and asynchronous activities than they would have traditionally. Reasons for this included giving students more time to learn at their own pace and having live classes focus on addressing students' difficulties or discussion.

"Yes. I think that the asynchronous delivery of more straightforward parts of the course was really helpful to allow students to go at their own pace. I would not return to the way that the course was delivered pre-COVID, but instead introduce some live delivery of the more tricky concepts."

In Question 17 participants were asked to suggest three things they had changed that they felt had helped students to learn and that they would recommend to colleagues for the longer term. Of the 35 participants who responded to this question, 12 (34.3\%) mentioned online assessment platforms or online quizzing as a technique they had felt worked well.

"Each video followed by an online quiz to force the students to engage with the material. There were incentives to take the quizzes though they didn't 'count' for anything."

The next most common suggestion (made by six respondents; $17.1 \%$ ) was to ensure that clear messaging is given to students about what is expected of them and when. Some responses, for example, mentioned providing a weekly schedule or to-do list, or simply suggested providing "[a] clear statement of what the students should be doing week-byweek". Five respondents suggested recording live sessions so that they could be accessed by "students that can't attend or need to watch twice". Four recommended using in-class polling to encourage active participation in live sessions.

"I think that doing more interactive lectures, with polls and going through questions and exercises, did help most students learn."

In Question 18, participants were asked if there were any changes they had made that they would recommend colleagues avoid. Out of the 23 responses the most common answer, given by $8(34.8 \%)$ participants, was that there was nothing they would recommend avoiding. A further 18 participants gave no response, perhaps suggesting that there may have been others belonging to this category. 
Three participants recommended avoiding the use of breakout rooms in digital classes. All of these mentioned students' dislike of or lack of participation in discussions.
"My students didn't like breakout rooms. They didn't talk to each other and preferred to just work on the problems as individuals. This is probably a symptom of the fact that they've never met each other in person. This term, I ended up scrapping the breakout rooms at student request."

However, this experience was not universal; other respondents elsewhere in the survey commented that they felt digital tutorials had been successful "[s]mall group synchronous maths tutorials worked reasonably well by electronic contact" and "[t]hey really enjoyed doing groupwork". Two responses recommended avoiding take-home assessments, with one participant commenting on the difficulty of ensuring academic integrity. However, the same response did suggest that open-book exams were new to the students; this may partly explain why this style of assessment had not worked well in this case.

"It was difficult to organise, and more than $10 \%$ of the students were later [referred] to the department's Academic Integrity officer for collusion. I am now a strong supporter of $[\ldots]$ exam rooms and invigilation. Online exams simply do not work because it is very difficult to prevent cheating. Also, it became clear to me that the students are not used to open-book exams at home, and did not revise for them as thoroughly as they normally would."

Another two participants suggested that lecturers should not try to achieve perfection in or spend too much time recording video clips.

\section{Discussion and conclusions}

\subsection{Answers to research questions}

(RQ1) What modes of delivery were used in 2020-21 for undergraduate mathematics teaching in the UK and did lecturers feel these were appropriate?

During 2020-21 more than half of courses in calculus and linear algebra were delivered digitally with no on-campus activities; the remainder used a mixture of digital and oncampus delivery. On-campus activities were more common before New Year 2021 when COVID-19 restrictions were looser. Almost all respondents felt that their mode of delivery had been correct given the pandemic. Some of those who had offered oncampus teaching felt that it gave students valuable opportunities for social interaction, though others found that such activities had been poorly attended. Some institutions who had intended to have on-campus activities were forced to switch to digital delivery as a result of lockdowns and low student attendance. A small minority felt that offering on-campus classes at all during the pandemic had been the wrong decision for safety reasons. The responses suggest that fully digital delivery was more efficient to 
implement than offering a mixture of on-campus and digital teaching, and that it helped to make students' experiences more uniform regardless of where they were located.

(RQ2) Did those lecturing undergraduate mathematics courses in the UK feel that their institutions were prepared for digital delivery in 2020-21?

The vast majority of participants felt that both their institution as a whole and their department had the necessary technical infrastructure to deliver teaching digitally but only around half were confident that these also had the correct expertise to provide excellent teaching digitally. While it seems likely that lecturers' confidence in teaching digitally will increase with experience, perhaps more work is needed to develop a shared sense of what it means to provide excellent digital teaching in mathematics. The vast majority of participants felt supported to deliver courses digitally by their institutions as a whole and by their departments. Even more felt that their students had been supported to engage in digital activities, though it should be noted that the views of students were not sought in this research.

(RQ3) How did the teaching tools used change as a result of the COVID-19 pandemic?

There was a significant change in the tools commonly used by lecturers to teach calculus and linear algebra courses. Seven tools were used by majorities of respondents in their teaching in 2020-21: (i) virtual learning environments (VLEs), (ii) typed course notes, (iii) discussion forums*, (iv) video clips made by the lecturer*, (v) video conferencing software*, (vi) online assessment platforms, and (vii) electronic submission of work (human marked)*. Four of these tools (marked *) saw significant increases in use in 2020-21 compared with before the COVID-19 pandemic. A further two (on-screen marking tools and business communication platforms) saw significant increases in their use since before the COVID-19 pandemic, even though they had not been used by a majority of respondents during 2020-21.

These findings expand on work done to understand changes made during the period of emergency remote teaching (ERT) at the end of the 2019-20 academic year. For example, Ní Fhloinn \& Fitzmaurice (2021) found large increases in the use of digital hardware and software for teaching. In particular, they report that videoconferencing software was used by almost all lecturers in their study. Unsurprisingly, this practice appears to have continued into 2020-21. Ní Fhloinn \& Fitzmaurice found that only a very small number of lecturers had used pre-recorded video clips prior to ERT; our results similarly show that the use of video clips increased significantly during 2020-21. However, Ní Fhloinn \& Fitzmaurice found that delivering live digital sessions was the most common approach during the period of ERT; by contrast, we found that lecturers typically changed their approaches to introduce more asynchronous activity in place of some live digital classes for the 2020-21 academic year (see also (RQ4) below). This apparent change in behaviour between approaches to ERT and to teaching in 202021 is also evidenced by the work of Drijvers et al. (2021). Though this study concerned secondary-school mathematics teachers, they found that the use of online assessment platforms actually decreased in some jurisdictions during the period of ERT; our results suggest increased use by university lecturers in 2020-21. The fact that ERT, by definition, had to happen at short notice may explain this behaviour; online assessment 
platforms require a time investment to produce suitable exercises. In an emergency response situation, it seems natural that priority would be given to solving more fundamental problems of communication by, for example, introducing video conferencing. With more time to prepare, and to share ideas (e.g. through TALMO meetings), lecturers it would appear that university lecturers used the summer of 2020 to rethink their delivery in time for the 2020-21 academic year.

(RQ4) How did expectations made of students change as a result of the COVID-19 pandemic?

There was typically a decrease in the amount of time students were expected to participate in live teaching activities, with an increase in the amount of time students were expected to spend working on activities asynchronously. Almost all of those who expected less live participation from students had replaced live lectures with prerecorded video clips to be studied asynchronously. Reasons given for this decision included concerns about the reliability of the technology needed to provide live digital classes and concerns that students may not have been able to access live sessions digitally.

Lecturers whose courses still had live classes (whether online or on campus) reported changes in the nature of those classes: more than a third said that they felt classes were more interactive than in the past, whilearound a third said they felt they had less interaction with students. It appears that lecturers who designed their classes with digital interaction in mind, and made full use of the tools available, saw more interaction than those who attempted to translate traditional lectures to a digital setting. Lecturers felt that students seemed reluctant to use video and contribute orally but were more willing to use text chat to interact during activities.

Lecturers gauged student participation using online activity tracking, their perception of student engagement during live classes, and student performance in coursework. Just over a third of lecturers felt that students had engaged with asynchronous material as intended and around a fifth said that they had seen a mixed response. Around a fifth of lecturers responded that they did not know how students had acted on their course. A few lecturers felt that, as well as missing out on social interaction, some students had struggled with motivation to study and keeping pace with the course.

(RQ5) Do lecturers intend to keep any changes to teaching made as a result of the COVID-19 pandemic in the longer term?

Around $90 \%$ of lecturers suggested they might keep some of the changes to their teaching that they had made in response to the COVID-19 pandemic; around 10\% suggested they would like to return to their traditional teaching methods. More than a third of lecturers said they would like to keep using recorded video clips, either as an additional resource or to replace traditional on-campus lectures and free up class time for different activities. Just over a third said they would like to keep using online assessment platforms due to them providing students with opportunities to practice, the ability to give immediate feedback, and the ability to randomise questions. Around a fifth of lecturers said they would like to use some form of flipped classroom, in-class 
polling or expressed a desire to have more interactive classes than traditionally.

Half of the lecturers suggested they would like to return to their traditional mix of live and asynchronous activities in the longer term. Around a third said they would consider a different mix after their experiences in 2020-21, perhaps having students read or watch video clips asynchronously ahead of more interactive live on-campus classes involving polling.

When asked to choose three practices to recommend to colleagues for the future, over a third of lecturers again suggested keeping online assessment platforms. A sixth said that they would recommend clearly communicating expectations to students, perhaps using a to-do list or a week-by-week schedule. Others suggested recording live sessions or using in-class polling.

Over a third of lecturers said explicitly that there was nothing they had tried that they would recommend colleagues avoid in the future. Three found breakout rooms in video calls problematic due to a lack of student participation, while others had felt that digital collaboration had worked well. Two suggested avoiding take-home examinations in mathematics, with one mentioning concerns about cheating.

\subsection{Concluding remarks}

The intention of this research was to collect evidence of how mathematics teaching took place in UK higher education during 2020-21, to understand what changes took place and to record the views of lecturers about their practice in the future. Lecturers responded from at least 21 distinct UK institutions, around $30 \%$ of all institutions offering BSc Mathematics courses. While this is a reasonably high response rate, it must be acknowledged that there was no response from most UK mathematics departments and so the results should be understood in that context.

The study only considered the responses of those who had taught calculus or linear algebra courses in the UK: one might wonder if the picture would be different for other courses and in other countries.

The data are based on lecturers' self-reports; students' experiences of learning during COVID-19 and their expectations for the future are also an important topic to explore for a follow up study. 


\section{References}

Artemeva, N., \& Fox, J. (2011). The Writing's on the Board: The Global and the Local in Teaching Undergraduate Mathematics Through Chalk Talk. Written Communication, 28(4), 345-379. https://doi.org/10.1177/0741088311419630

Drijvers, P., Doorman, M., Boon, P., Reed, H., \& Gravemeijer, K. (2010). The teacher and the tool: Instrumental orchestrations in the technology-rich mathematics classroom. Educational Studies in Mathematics, 75(2), 213-234. https://doi.org/10.1007/s10649-010-9254-5

Drijvers, P., Thurm, D., Vandervieren, E., Klinger, M., Moons, P., Mol, A., Barzel, B., \& Doorman, M. (2021). Distance mathematics teaching in Flanders, Germany and the Netherlands during COVID-19 lockdown. Educational Studies in Mathematics. In press. https://doi.org/10.1007/s10649-021-10094-5

Fagerland, M. W., Lydersen, S., \& Laake, P. (2013). The McNemar test for binary matched-pairs data: Mid-p and asymptotic are better than exact conditional. BMC Medical Research Methodology, 13(1), 91. https://doi.org/10.1186/14712288-13-91

Holm, S. (1979). A Simple Sequentially Rejective Multiple Test Procedure. Scandinavian Journal of Statistics, 7.

Iannone, P., \& Simpson, A. (2012). Mapping university mathematics assessment practices. University of East Anglia.

Ní Fhloinn, E., \& Fitzmaurice, O. (2021). How and why? Technology and practices used by university mathematics lecturers for emergency remote teaching during the COVID-19 pandemic. Teaching Mathematics and Its Applications: International Journal of the IMA, 40(4).

Quality Assurance Agency for Higher Education (Ed.). (2019). Subject Benchmark Statement: Mathematics, Statistics and Operational Research. 25.

The University of Edinburgh School of Physics. (2020, March 13). School teaching arrangements for week beginning 16 March 2020.

https://www.ph.ed.ac.uk/news/2020/school-teaching-arrangements-for-weekbeginning-16-march-2020-20-03-15 